Mariana de Aguiar Ferreira Muaze

Professora adjunta III no

Departamento de História da

Universidade Federal do Estado

do Rio de Janeiro (Unirio - Rio de

Janeiro/Brasil).

e-mail:mamuaze@gmail.com
SALLES, Ricardo.

Nostalgia Imperial: escravidão e formação da identidade nacional no Brasil do Segundo Reinado.

Rio de Janeiro: Editora Ponteio, 2013, 212p.

\section{As partes e o todo: uma leitura de "Nostalgia Imperial"}

Publicado pela primeira vez em 1996 e reeditado em 2013, o livro Nostalgia Imperial: escravidão e formação da identidade nacional no Brasil do Segundo Reinado, do historiador Ricardo Salles, apresenta uma consistente reflexão intelectual, de matriz marxista, sobre o Estado imperial no século XIX. Encarando a história como práxis, o autor privilegia os conceitos gramscianos de bloco histórico e hegemonia para produzir uma história total capaz de ressaltar as articulações entre as esferas política, econômica e cultural. 0 resultado é um belo livro que reflete sobre a construção da nação brasileira no século XIX a partir de 3 fatores principais: o recrudescimento da escravidão, a formação de uma cultura nacional de caráter oficialista, e as inter-relações entre capitalismo, liberalismo e escravidão.

A partir da experiência vivenciada com a aprovação do plebiscito sobre o sistema de governo a ser empregado no Brasil (monarquia ou república) no início dos anos 1990, Ricardo Salles constata a existência de uma "nostalgia imperial" na consciência coletiva dos brasileiros. Tal sentimento, difuso entre as camadas populares e acentuado nas elites intelectuais, se basearia na percepção de que "houve um tempo [o Império] em que o Brasil era mais respeitável, mais honesto, mais poderoso"(p. 18). Como este sentimento foi construido no imaginário social brasileiro? Quais circunstâncias históricas atuaram neste processo? Por que com mais de cem anos de existência a república não foi capaz de reverter esta imagem?

Estas perguntas guiam o autor ao longo dos cinco capitulos que compõem o livro. Como fios condutores, são uma escolha inteligente para tratar das múltiplas partes - cultura e imaginário social; política e formação da classe senhorial; liberalismo, escravidão e capitalismo - que compõem o todo, o edifício imperial, sem abrir mão de sua complexidade. 0 resultado é uma narrativa de grande erudição, que discute com as historiografias sobre a formação do estado nacional, escravidão, capitalismo, ao mesmo tempo em que é capaz de transitar entre os universos micro e macro para apresentar uma interpretação geral do Império.

A chave explicativa apresentada por Ricardo Salles para o sentimento nostálgico em relação ao Império é, ela própria, um fenômeno complexo. $\mathrm{Na}$ visão do historiador, a limitação das oligarquias tradicionais em consolidarem a obra republicana, até pelo menos os anos 1930, não explica a força da monarquia na "esfera mítica da história nacional". Ao contrário, a imagem positiva do Império se deveu a três aspectos fundamentais. Primeiro, após o 15 de novembro, políticos, intelectuais e historiadores ligados à monarquia - a exemplo de Capistrano de Abreu, visconde do Rio Branco, Pedro Calmon, Oliveira Vianna e outros - combateram a república com um discurso que reforçava seu caráter excludente e exaltava os progressos do Império, como estratégia de crítica ao novo regime. Segundo, o próprio estado imperial foi bastante eficiente ao produzir uma dada imagem de si mesmo que dialogasse com o passado, o presente e o futuro da nação.

DOI - http://dx.doi.org/10.1590/2236-463320140711 
Desta forma, a "nostalgia imperial" não se resumiria à obra destes historiadores, políticos e ensaístas. Ela seria fruto do investimento do estado em setores estratégicos a exemplo do Instituto Histórico e Geográfico Brasileiro, Imperial Academia de Belas Artes e artistas ligados ao movimento romântico. Terceiro, o ideal de civilização imperial que, durante a vigência da monarquia, tinha a escravidão como base, não foi desarticulado com a República. A crítica moral à escravidão, efetivada internamente pelo movimento abolicionista e externamente por diversos setores internacionais, não trouxe a superação das mazelas da escravidão. Mesmo tendo impedido a reprodução do regime escravocrata no Brasil, a abolição não conseguiu remover a noções de diferença e hierarquia da base de nosso edifício social. Como resultado, em pouco tempo, foi possivel aos grandes proprietários rurais recomporem suas forças garantindo mão de obra barata e primazia na ocupação dos poderes locais. Assim, a espoliação da cidadania e a exclusão econômico-social se mantiveram no tempo e nos anos de 1990 permaneciam na base do sentimento de "nostalgia imperial".

No que compete às discussões sobre a construção do estado, o projeto político e a cultura imperial, o livro de Ricardo Salles retoma a interpretação de Ilmar Mattos em "Tempo Saquarema" (1987) e concebe os processos de construção e consolidação do Estado imperial como elementos interligados e concomitantes à constituição de uma hegemonia de classe: a dos senhores de escravos. Segundo ele, este grupo era formado por grandes proprietários de escravos e terras, principalmente da região sul-fluminense, cujos interesses se viram representados pela política conservadora a partir dos anos de 1840. Neste contexto, coube à chamada classe dirigente expandir os ideais de "manutenção da ordem" escravocrata e "expansão da civilização" (baseada em ideais europeizantes) de modo a transformá-los em valores e práticas inerentes ao próprio Estado Imperial.

Este projeto vitorioso foi conduzido e produzido por intelectuais vinculados tanto à fração dirigente da classe dos senhores, os grandes proprietários fluminenses, quanto ao próprio aparelho estatal. Contudo, na análise apresentada, o autor ressalta os diversos interesses políticos, econômicos e sociais em jogo. Afinal, para que a sociedade escravista imperial se efetivasse foi necessário "o deslocamento crescente do nível de realização dos interesses da classe dominante escravista do plano imediato da produção e manutenção direta das relações de produção" (p. 39) para o âmbito do estado. A política implementada pelos políticos conservadores a partir do Regresso conseguiu realizar uma acomodação entre as diferentes forças políticas e sociais em torno dos projetos de preservação da escravidão e de fortalecimento do aparato estatal (p. 52). Atuando como importante amálgama dos interesses das classes dirigentes, a escravidão se desenvolveu de forma original e plena no Brasil oitocentista, além de favorecer a expansão do capitalismo no mundo. Todavia, para além dos aspectos políticos e econômicos, o projeto escravista imperial foi capaz de criar um conjunto de valores próprios, uma base cultural, um modo de vida em particular a que Ricardo Salles denominou de "civilização imperial".

Pensadas por este prisma, as noções de civilização imperial e cultura nacional se interpenetram. No que compete à cultura nacional em formação, dois aspectos são ressaltados pelo autor: a valorização de elementos ligados à herança colonial (tais como língua, cultura, influências africana e indígena) e a produção de singularidades através da cultura letrada 
com destaque para o romantismo e o indianismo (p. 65). Como resultado, verificou-se uma produção cultural obstinada em desenhar "a cor local", "o que nos era próprio", resultando num discurso que valorizava as heranças rural, africana, indígena e portuguesa (p. 91), respaldadas num forte caráter oficialista. Todavia, neste processo, também foi importante manter um diálogo com a modernidade, horizonte de civilização e progresso, que tinha Europa como o modelo a ser seguido. Portanto, no plano discursivo, o Império se pretendia "uma civilização europeia transplantada para a América". A cultura imperial que dai emergiu foi fruto desta expectativa somada à prática cotidiana da escravidão.

Embora a interpretação gramsciana da dinâmica política e social do Império aproxime as análises de Ricardo Salles e Ilmar Mattos, é importante apontar que o peso dado pelo primeiro às relações escravistas e ao papel dos escravos como agentes fundamentais no entendimento da sociedade oitocentista (a exemplo de seu papel nos diversos abolicionismos, nos movimentos nativistas, e em suas próprias rebeliões) os diferencia. Além da forma de exploração, símbolo de poder e status social, para Ricardo Salles a escravidão negra é constituidora das formas de agir, sentir e pensar da sociedade imperial. Sua manutenção era o ponto de interseção entre os membros da classe senhorial, cujos interesses serviram de base para a consolidação de uma hegemonia de classe forjada no próprio processo de construção das instituições políticas e do estado imperial, mas também a força material do Império.

Mais do que um aspecto interno, "a escravidão estava na raiz do mundo moderno" (p. 95) e colocava o Brasil na rede de relações comerciais vigentes. Na posição de países exportadores, Brasil e sul dos Estados Unidos desenvolveram organizações politicas complexas para garantirem a manutenção do regime escravista em seus territórios. Os produtos primários ali gerados (café, açúcar, algodão e outras commodities) a baixos preços representavam grandes negócios, envolviam imensas somas de capital e investimentos em tecnologias com o intuito de aumentarem a produção e manterem as áreas de produção integradas ao sistema capitalista. Tais aspectos permitiram o florescimento de civilizações em que o liberalismo e os valores a ele ligados (indivíduo, cidadania, direitos políticos e direito de propriedade) puderam se desenvolver de modo específico, na maior parte das vezes, atendendo aos propósitos da classe dominante.

A escravidão era, portanto, a matriz fundadora e estabilizadora da sociedade imperial. Quando, a partir dos anos de 1870, a mesma passou a sofrer forte crítica no cenário internacional e sua contestação se expandiu no âmbito interno através da fuga de escravos e do movimento abolicionista, instaurou-se uma crise de hegemonia. Ricardo Salles explica este processo como decorrente de dois fatores principais. Em primeiro lugar, 0 fim do tráfico no Brasil possibilitou a composição de uma "escravidão madura" em torno da década de 1860 . Ou seja, o número de escravos crioulos era maior do que de africanos, proporcionando uma maior integração dos mesmos ao extrato cultural vigente. Em segundo lugar, a elevação do preço dos escravos ocorrida após 1850 causou uma concentração desta mão de obra fazendo com que, a defesa da escravidão deixasse de ser um interesse da maioria dos brasileiros para se tornar um privilégio de alguns poucos grandes proprietários fluminenses. Neste ambiente, o Império se mostrou incapaz de atender às necessidades de uma sociedade em modernização econômica, expansão demográfica e com um leque ampliado de demandas 
sociais. Em pouco tempo, a crise de hegemonia encontraria a crise política. 0 fim do regime monárquico estava próximo.

0 livro em tela é por tudo o que foi dito, uma instigante leitura onde narrativa, teoria e práxis ocupam espaços privilegiados na construção de um modelo explicativo para a formação e consolidação da nação no Brasil. Trata-se de uma obra obrigatória para os estudiosos do Oitocentos e para todos aqueles que se interessam pelas questões referentes à construção do estado. Mas, não somente isso. "Nostalgia Imperial" também instiga a pensar sobre como a exclusão é constitutiva de nossa sociedade atual. Aponta como a matriz escravista produziu afastamentos históricos entre povo e cidadania, entre povo e estado/nação, até hoje presentes. Para os interessados, fica o convite à reflexão. 